\title{
Epidemiological Transition of Type 2 Diabetes Mellitus in Rural South West Cameroon
}

\author{
Aminkeng Zawuo Leke1,2, Nkwati Michel Maboh',2, Susan Etta Maeya2, Obale Armstrong1,2, \\ Lerry Dibo Ndumbe1, Bessem Pauline Nyenti2 , Akum Delbert Afumbom', \\ Njume Beckly Sone ${ }^{2}$, Derick Etiendem², Elsa Shiri Nkwati²
}

\begin{abstract}
${ }^{1}$ Department of Nursing, School of Health Sciences, Biaka University Institute of Buea-Cameroon, Buea, Cameroon
${ }^{2}$ Centre for Innovation in Education and Research, Health Research Foundation, Buea, Cameroon

Email: zawuol@gmail.com
\end{abstract}

How to cite this paper: Leke, A.Z., Maboh, N.M., Maeya, S.E., Armstrong, O., Ndumbe, L.D., Nyenti, B.P., Afumbom, A.D., Sone, N.B., Etiendem, D. and Nkwati, E.S. (2020) Epidemiological Transition of Type 2 Diabetes Mellitus in Rural South West Cameroon. Open Journal of Endocrine and Metabolic Diseases, 10, 45-58.

https://doi.org/10.4236/ojemd.2020.104006

Received: February 22, 2020

Accepted: April 5, 2020

Published: April 8, 2020

Copyright $\odot 2020$ by author(s) and Scientific Research Publishing Inc. This work is licensed under the Creative Commons Attribution International License (CC BY 4.0).

http://creativecommons.org/licenses/by/4.0/

\begin{abstract}
Aims: To determine the prevalence and 10 years risk of type- 2 diabetes mellitus in rural English speaking South West Cameroon. Methods: Between April and June 2018, we conducted community screening campaigns in 6 English speaking rural communities of Cameroon. We adapted the Finish Diabetes Association Type 2 diabetes risk assessment tool to enable us classify participants as low or high risk cases. Results: In a sample of 983 participants aged $\geq 30$ years, we found 37 (3.8\%) persons with type 2 diabetes (12 existing and 25 newly diagnosed) and 149 (15.1\%) persons at high risk of developing diabetes within 10 years. We estimated that within 10 years $65(6.9 \%)$ new cases of diabetes will emerge from the study population. Older participants (54 - 87 years) were 2.5 times (AOR 2.5, CI: 1.0, 6.2) more likely to have diabetes compared to younger (30 - 44 years) participants. The risk of developing diabetes within 10 years was statistically significantly increased among participants who were semi-active, older, had a high BMI, had a family history of diabetes or had high systolic blood pressure. Conclusions: Our study identified a brewing diabetes crisis in rural Cameroon, confirming the recent International Diabetes Federation warnings of an impending rural diabetes crisis in Sub-Saharan Africa. There is therefore an urgent need for measures to avert the situation such as expanding the urban-focused diabetes service to rural areas.
\end{abstract}

\section{Keywords}

Cameroon, Rural, Prevalence of Type 2 Diabetes Mellitus, Type 2 Diabetes Risk, Undiagnosed Diabetes

\section{Introduction}

According to the 2019 International Diabetes Federation (IDF) atlas, 463.0 mil- 
lion (9.3\%) adults aged 20 - 79 years were living with diabetes globally. This figure is projected to rise to 700.2 million (14.1\%) by 2045. The highest proportion (79.4\%) of adults living with diabetes is found in low- and middle-income countries [1].

Before the 21st century, diabetes was rare in Africa, and seen as a disease of the West [2] [3]. However, just like other parts of the world, since the 21st century, Africa has been experiencing a steady rise in the prevalence of diabetes [2] [4]. Type 2 diabetes mellitus represents $90 \%$ of all diabetes cases in Africa [5]. In 2019, there were 19 million adults living with diabetes in Africa, representing a prevalence of 3.9\% [1]. This prevalence is lower than reported in any other regions of the world. However, the region has the highest proportion of undiagnosed cases compared to any other region of the world, with an estimated $60 \%$ of adults currently living with diabetes unaware of their condition [1]. The high rate of undiagnosed cases in Africa has been mainly attributed to more rural populations with limited resources and low prioritisation of screening [1]. For example, although $40 \%$ of the Cameroon's population currently live in rural areas [6], the national diabetes plan is only centred in urban areas with limited or no resources allocated to rural areas.

With the rapid rate of urbanisation occurring in sub-Saharan Africa, it is projected that many rural areas will soon be transformed into urban areas, and this may lead to a spike of diabetes prevalence [1] [7]. This partly explains a projection indicating a $47.5 \%$ surge in diabetes in sub-Saharan Africa by 2030, compared to $18.7 \%$ increase in the rest of the world [1]. For a region still grappling with major infectious diseases such as HIV/AIDS, tuberculosis and malaria, this surge in diabetes will have grave consequences for its healthcare systems [4]. Presently, the proportion of all deaths due to diabetes occurring before the age of 60 in Africa is $73 \%$, compared to $31 \%$ in Europe [1]. This shows that diabetes is already a major burden in sub-Saharan Africa. Yet, health expenditure for diabetes in the sub-Saharan Africa region in 2017 represented only $1 \%$ of the total global expenditure on diabetes [1].

Apart from lack of funding for diabetes, another major challenge facing sub-Saharan Africa is the lack of population and context specific data on diabetes which can inform policy measures toward combatting the disease. This is especially true for rural Africa, which contributes almost half of the population in most African nations [8]. The severe underreporting of diabetes prevalence in rural Africa and the warnings of an impending upsurge in diabetes contributed by these rural areas demand an urgent need for prevalence approximation. This is especially true in the English speaking regions of Cameroon.

In the present study, we conducted sensitisation and screening campaigns in 6 rural communities of the South West English speaking region of Cameroon with objectives to: 1 ) estimate the prevalence of Type 2 diabetes mellitus and undiagnosed diabetes; 2) estimate the proportion of the study population at high risk for developing Type 2 diabetes mellitus within 10 years; 3 ) identify the risk factors of Type 2 diabetes mellitus; 4) increase awareness of diabetes; and 5) follow 
up care of persons with diabetes. Results of the last two objectives will be discussed in a separate report.

\section{Methods}

\subsection{Setting}

As part of a nurse led rural diabetes intervention project co-funded by World Diabetes Foundation and Biaka University Institute of Buea, diabetes screening campaigns were conducted in the month of April-June 2018 in 6 rural communities (Mabeta $1 \& 2$, Debundscha, Idenau $1 \& 2$ and Sanje) in the Limbe health district of the SWR of Cameroon.

Each of the six rural communities of about 2500 inhabitants is served by a primary care centre managed by nurses. About $30 \%$ of the population (750 people) of each rural community is expected to be aged 30 and above [9]. Fishing and agriculture are the main economic activities in these rural areas. Those engaged in agriculture work mainly for the Cameroon Development Cooperation (CDC) - a parastatal commercial agricultural organisation. Our six rural communities included 3 CDC workers communities and 3 non-CDC workers communities. The CDC has established health centres in each agricultural area that provide healthcare for its workers, while non-CDC workers receive healthcare from government health centres.

\subsection{Training and Screening}

Firstly, we used a socially accountability-based model-ENACIER (Empower, Negotiate, Assess, Collaborate, Intervene, Evaluate and Report) [10] to train final year nursing students. The training which also included health centre nurses, covered screening and management over two days. The students and nurses then organised a series of community diabetes screening campaigns in the month of April to June 2018.

Only adults aged $\geq 30$ years were eligible to participate in the screening. This criterion was set to target the population at risk and maximise available resources. We adapted the Finish Diabetes Risk (FINDRISC) assessment criteria to calculate risk scores for participants [11]. Participants went through a two-stage screening procedure. In the first stage (pre-screening), risk factors for diabetes were assessed (see pre-screening form in supplementary file). Only participants with a risk score of $>5$ were eligible for second stage screening. In the second stage (Screening) fasting blood glucose was measured (see screening form in supplementary file). The glucose test was conducted only for participants who had fasted for at least 8 hours. Prior to the screening exercise, a community awareness campaign was carried out to prepare participants. Participants were asked to fast for at least 8 hours prior to the test.

Prior to this project, focused diabetes care was not part of the minimum package of activities at the health centres. Hence, existing persons with diabetes were also invited for evaluation as part of the screening campaign. The screening 
campaigns were done in the morning from door-to-door, at town hall meetings, and at market and church gatherings.

Fasting blood glucose was measured using On Call Extra glucometers-model OGM-191. Participants who did not fast on test days were given new appointments. Data on sex, age, body mass index, waist hip ratio, blood pressure and family history of diabetes were also collected. Based on their adapted FINDRISC scores, participants were classified as low or high risk for diabetes within 10 years [11]. Potential diabetes cases (defined by a fasting blood glucose of $>126$ $\mathrm{mg} / \mathrm{dl}$ plus cardinal symptoms of diabetes) were invited for a follow up fasting blood glucose test to confirm a diagnosis of diabetes.

\subsection{Classification of Participants and Data Analyses}

As shown in Table 1, at the end of the screening exercise participants were classified as follows: 1) existing Type 2 diabetics (based on existing records); 2) newly diagnosed Type 2 diabetics (using the WHO, 2006 criteria [12]); 3) low or high risk of developing Type 2 diabetes within 10 years (using FINDRISC [11]); 4) underweight, normal weight, overweight or obese (using the US Centre for Disease Control, 2017 guideline [13]); and 5) centrally obese (using the WHO, 2011 guideline [14]).

Adapted from FINDRISC, the percentage of persons that will develop diabetes within 10 years was estimated according to their screening scores as follows: score $\leq 10=1 \%$; score of $11-13=16.7 \%$; score of $14-19=33 \%$; score $\geq 20=$ $50 \%$ [11]. We also grouped the study population into two: active (CDC workers) and semi active (non-CDC workers).

Data was analysed using SPSS version 25 . We evaluated the association between different groups and the prevalence of type 2 diabetes or risk for type 2

Table 1. Criteria for classifying participants*.

\begin{tabular}{|c|c|c|c|c|c|}
\hline Characteristic & Patient's medical record & FBS (mg/dl) & $\begin{array}{l}\text { Screening } \\
\text { Score }\end{array}$ & BMI $\left(\mathrm{kg} / \mathrm{m}^{2}\right)$ & WHR \\
\hline Existing diabetes case & $\begin{array}{l}\text { Evidence of diagnosis, } \\
\text { treatment and/or } \\
\text { confirmation by patient. }\end{array}$ & & & & \\
\hline Newly diagnosed diabetes case & & $\begin{array}{l}>126 \text { (with symptoms } \\
\text { and confirmation test) }\end{array}$ & & & \\
\hline Low risk for diabetes within 10 year & & & $<14$ & & \\
\hline High risk for diabetes within 10 years & & $110-126$ & $\geq 14$ & & \\
\hline Underweight & & & & $<18.5$ & \\
\hline Normal weight & & & & $18.5-24.9$ & \\
\hline Overweight & & & & $25-30$ & \\
\hline Obese & & & & $>30$ & \\
\hline Centrally obese & & & & & $>9(\mathrm{M}) ;>0.85(\mathrm{~F})$ \\
\hline
\end{tabular}

*Informed by FINDRISC; CDC, 2017 and WHO, 2011 [11] [12] [13] [14]. FBS-Fasting Blood Sugar; BMI-Body Mass Index; WHR-Waist Hip Ratio; M-Male; F-Female. 
diabetes using binary logistic regression. We also evaluated the sensitivity and specificity of the adapted FINDRISC to detect diabetes at a cut off risk score of $\geq 11$ and $\geq 14$. Statistical significance level for all tests was set at 0.05 .

\subsection{Ethical Approval}

All participants' data used for research were anonymised. Ethical clearance to use participants' data for research was obtained from the Cameroon South West Regional delegation of Public Health, with written individual consent obtained from all participants.

\section{Results}

The study sample included 983 participants (971 screened for diabetes and 12 known (existing) diabetics), representing $22 \%$ of the study population. The ages of the participants ranged between $30-87$ years, with the majority (58\%) between 30 - 44 years old. There were more females (59\%) than males $(40.9 \%)$ and a large proportion of the participants were overweight (35.4\%), obese (31.9\%), centrally obese (47.6) or had a family history of diabetes (54.9) (Table 2).

The total number of existing (12) or newly diagnosed (25) diabetes cases in the study population was $37(3.8 \%)$, with $149(15.1 \%)$ persons at high risk of developing diabetes within 10 years (Figure 1). We estimated that 65 (6.9\%) out of the current 946 non-diabetes cases will develop diabetes within 10 years. A total of 377 (38.4\%) participants had a risk score below 11; and of the 37 diabetics, 8 had a risk score of $11-13$ while 29 had a risk score of $\geq 14$ (Figure 2).

Figure 3 shows that the Area Under the Curve (AUC) for detecting type 2 diabetes status using the adapted FINDRISC was 0.932 (CI: 0.904, 0.960). At a cut off risk score $\geq 11$ the sensitivity and specificity of the adapted FINDRISC for detecting diabetes were $100 \%$ and $73.6 \%$ respectively; while at a cut off risk score $\geq 14$ the sensitivity and specificity were $82.2 \%$ and $86.4 \%$ respectively.

Older participants (54 - 87 years) were 2.5 times (AOR 2.5, CI: 1.0, 6.2) more likely to have diabetes compared to younger (30 - 44 years) participants (Table 2). There were no other associations between diabetes and other variables investigated.

Table 2. Logistic regression analysis showing association between risk factors and diabetes or high risk for diabetes within 10 years.

\begin{tabular}{ccccccccc}
\hline & & \multicolumn{3}{c}{ Diabetes case(s) } & \multicolumn{3}{c}{$\begin{array}{c}\text { High risk for diabetes } \\
\text { within 10 years }\end{array}$} \\
\cline { 5 - 9 } Risk Factor & Total & & $\mathbf{n}(\%)$ & AOR $^{*}$ & $95 \%$ CI & n (\%) & AOR $^{*}$ & $95 \%$ CI \\
\hline Population type & & & & & & & & \\
Active & $552(56.2)$ & $20(3.6)$ & 1.0 & Ref & $64(12.0)$ & 1.0 & Ref \\
Semi-Active & $431(43.8)$ & $17(3.9)$ & 1.0 & {$[0.5,2.0]$} & $85(20.5)$ & $2.4^{* *}$ & {$[1.4,4.2]$} \\
Age & & & & & & & \\
30 - 44 Years & $571(58.1)$ & $14(2.5)$ & 1.0 & Ref & $35(6.3)$ & 1.0 & Ref \\
$44-54$ Years & $265(27.0)$ & $13(4.9)$ & 1.9 & {$[0.9,4.3]$} & $58(23.0)$ & $7.7^{* * *}$ & {$[4.1,14.7]$} \\
\hline
\end{tabular}




\section{Continued}

\begin{tabular}{|c|c|c|c|c|c|c|c|}
\hline $54-87$ Years & $147(15.0)$ & $10(6.8)$ & $2.5^{*}$ & {$[1.0,6.2]$} & $56(40.9)$ & $35.6^{\star * *}$ & {$[16.4,77.5]$} \\
\hline \multicolumn{8}{|l|}{ Sex } \\
\hline Male & $402(40.9)$ & $15(3.7)$ & 1.0 & Ref & $42(10.9)$ & 1.0 & Ref \\
\hline Female & $581(59.1)$ & $22(3.8)$ & 1.0 & {$\left[\begin{array}{ll}0.4 & 2.2\end{array}\right]$} & $107(19.1)$ & 1.0 & {$[0.5,2.0]$} \\
\hline \multicolumn{8}{|l|}{ BMI Classification } \\
\hline Normal Weight & $301(30.6)$ & $8(2.7)$ & 1.0 & Ref & $17(5.8)$ & 1.0 & Ref \\
\hline Underweight & $19(1.9)$ & $1(5.3)$ & 0.6 & {$[0.1,5.7]$} & $1(5.6)$ & 0.6 & {$[0.1,6.1]$} \\
\hline Overweight & $348(35.4)$ & $13(3.7)$ & 0.9 & {$[0.1,7.7]$} & $36(10.7)$ & $2.3^{*}$ & {$[1.0,5.0]$} \\
\hline Obese & $314(31.9)$ & $14(4.5)$ & 0.9 & {$[0.1,8.0]$} & $95(31.7)$ & $24.6^{* * *}$ & {$[10.7,56.8]$} \\
\hline \multicolumn{8}{|l|}{ WHR } \\
\hline Normal & $478(48.6)$ & $15(3.0)$ & 1.0 & Ref & $38(7.9)$ & 1.0 & Ref \\
\hline Central Obesity & $468(47.6)$ & $21(4.3)$ & 1.3 & {$[0.6,3.1]$} & $111(23.7)$ & $6.8^{* * *}$ & {$[3.8,13.0]$} \\
\hline \multicolumn{8}{|l|}{$\begin{array}{l}\text { Family history } \\
\text { of diabetes }\end{array}$} \\
\hline No & $406(41.3)$ & $12(2.9)$ & 1.0 & Ref & $12(3.0)$ & & \\
\hline Yes & $540(54.9)$ & $25(4.4)$ & 1.6 & {$[0.8,3.4]$} & $137(25.4)$ & $74.3^{* * *}$ & {$[29.0,190.4]$} \\
\hline \multicolumn{8}{|l|}{ Systolic BP } \\
\hline$<120$ & $720(73.2)$ & $21(2.8)$ & 1.0 & Ref & $80(11.1)$ & 1.0 & Ref \\
\hline$>120$ & $225(22.9)$ & $16(6.6)$ & 1.8 & {$[0.7,4.5]$} & $69(30.7)$ & $4.2^{\star * *}$ & {$[2.0,8.6]$} \\
\hline \multicolumn{8}{|l|}{ Diastolic BP } \\
\hline$<90$ & $750(76.3)$ & $24(3.1)$ & 1.0 & Ref & 97 (12.9) & 1.0 & Ref \\
\hline$>90$ & $194(19.7)$ & $13(6.3)$ & 1.3 & {$[0.5,3.2]$} & $52(26.8)$ & 1.3 & {$[0.6,2.8]$} \\
\hline
\end{tabular}

$¥:$ Adjusted for all variables within model; AOR: Adjusted Odds ratio; CI: Confidence interval; ${ }^{*} \mathrm{p}<0.05$, ${ }^{* *} \mathrm{p}<0.01,{ }^{* *} \mathrm{p}<0.001$.

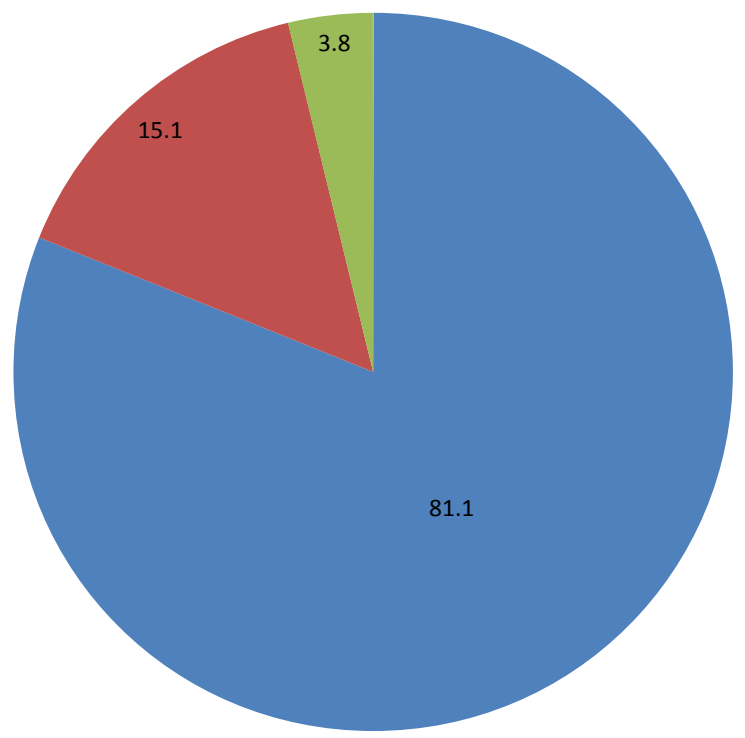

Low risk of diabates in 10 years

- High risk of diabetes in 10 years

Diagnosed with diabetes

Figure 1. Diabetes status of study population. 


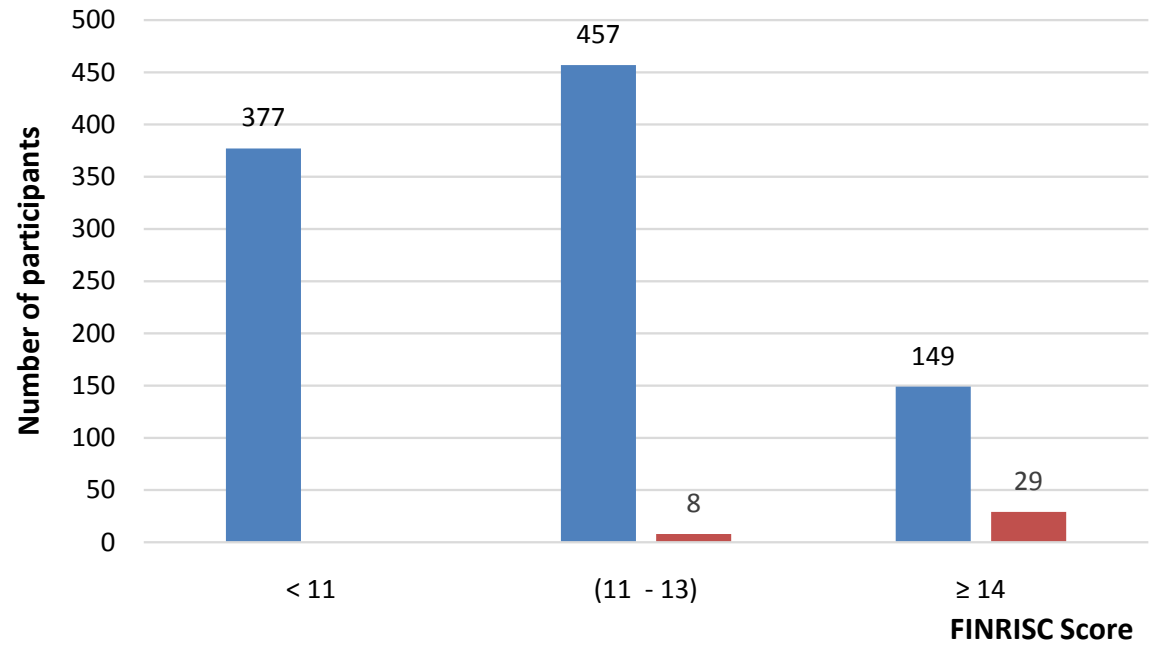

Figure 2. FINRISC scores distribution for all participants and those with diabetes.

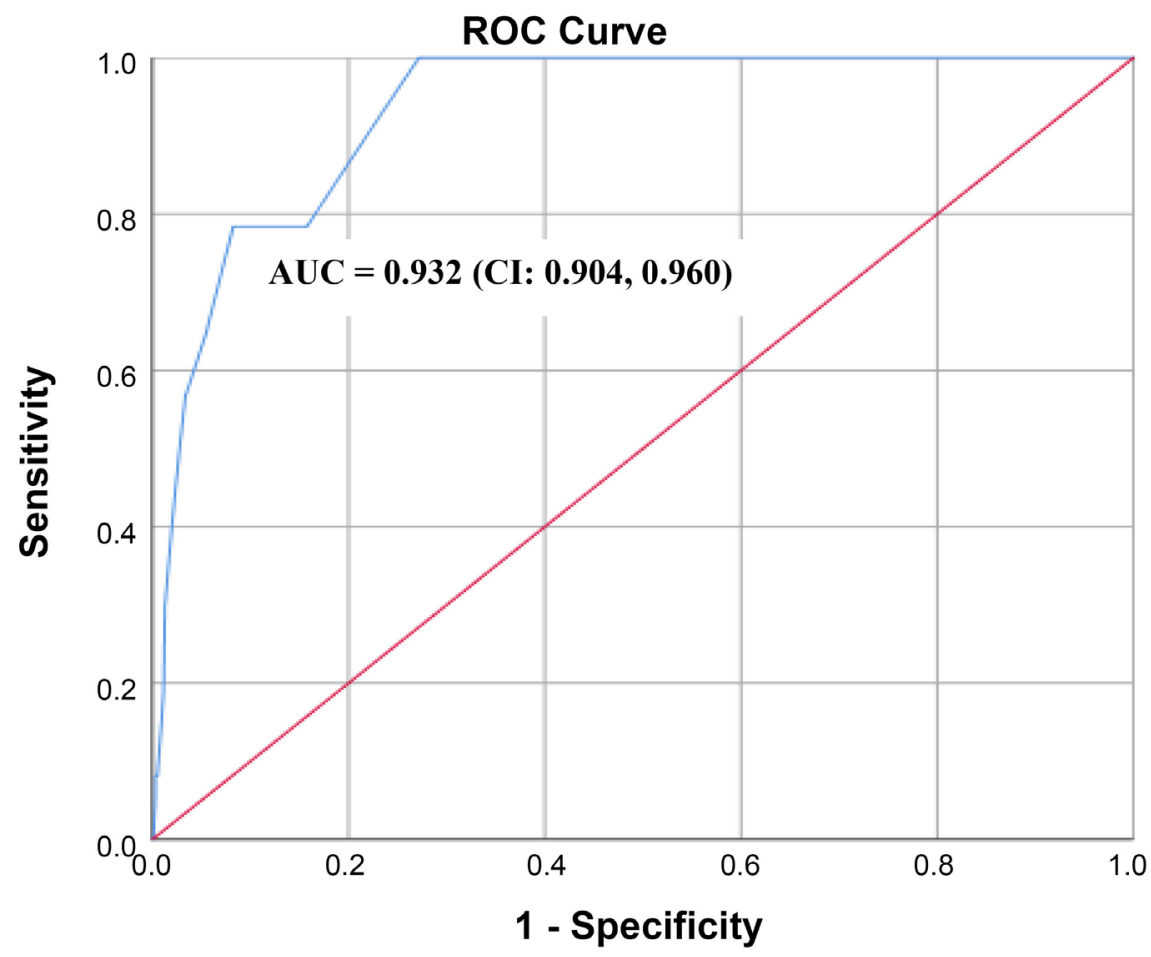

Figure 3. Receiver operating characteristic (ROC) curve for detecting type 2 diabetes using adapted FINRISC.

The risk of developing diabetes within 10 years was statistically significantly increased among participants who were semi-active, older, had a high BMI, had a family history of diabetes or had high systolic blood pressure.

There was no statistically significant difference in age and sex between the active population and semi-active populations. Compared to the active population, those in the semi-active population were more likely to be overweight, centrally obese or have a family history of diabetes (Table 3). On the other hand, blood 
Table 3. Chi-Squared analysis showing differences in the distribution of risk factors between Active and Semi-active populations.

\begin{tabular}{|c|c|c|c|}
\hline \multirow{2}{*}{ Variable } & \multicolumn{2}{|c|}{ Population } & \multirow{2}{*}{ P-Valu } \\
\hline & Active & Semi-Active & \\
\hline Age & & & 0.818 \\
\hline 30 - 44 Years & $322(58.3)$ & $249(57.8)$ & \\
\hline 44 - 54 Years & $145(26.3)$ & $120(27.8)$ & \\
\hline $54-87$ Years & $85(15.4)$ & $62(14.4)$ & \\
\hline Sex & & & 0.343 \\
\hline Male & $233 \quad(42.2)$ & $169(39.2)$ & \\
\hline Female & $319(57.8)$ & $262(60.8)$ & \\
\hline BMI Classification & & & 0.000 \\
\hline Underweight & $4(0.7)$ & $15(3.5)$ & \\
\hline Normal Weight & $149(27.0)$ & $152(35.3)$ & \\
\hline Overweight & $191(34.6)$ & $157(36.5)$ & \\
\hline Obese & $208(37.7)$ & $106(24.7)$ & \\
\hline WHR & & & 0.000 \\
\hline Normal & $321(58.2)$ & $172(40.0)$ & \\
\hline Central Obesity & $231(41.8)$ & $258(60.0)$ & \\
\hline Family history of diabetes & & & 0.000 \\
\hline No & $273(49.5)$ & $145(33.6)$ & \\
\hline Yes & $279(50.5)$ & $286(66.4)$ & \\
\hline Systolic BP & & & 0.061 \\
\hline$<120$ & $404(73.2)$ & $337(78.4)$ & \\
\hline$>120$ & $148(26.8)$ & $93(21.6)$ & \\
\hline Diastolic BP & & & 0.033 \\
\hline$<90$ & $422(76.4)$ & $352(82.1)$ & \\
\hline$>90$ & $130(23.6)$ & $77(17.9)$ & \\
\hline
\end{tabular}

pressure readings were higher among those in the active population, reaching statistical significance for diastolic blood pressure.

\section{Discussion}

To the best of our knowledge this is the first study in Cameroon to report on the 10 years risk of diabetes prevalence. The estimated AUC of 0.932 for the adapted FINRISC used in this study indicates it was an excellent tool. Its sensitivity and specificity results for detecting diabetes were similar to those reported in many other studies [15]. The observed sensitivity of $100 \%$ at a cut off risk score $\geq 11$ means it would have been sufficient for us to measure the fasting blood glucose of 377 (38.4\%) participants with a risk score $\geq 11$ to identify all the 37 diabetics 
in our study. We therefore add our voice to that of previous authors to recommend the FINRISC tool as valuable and reliable in diabetes screening.

We observed a diabetes prevalence (3.8\%) in our study population similar to that $(4.9 \%)$ which we previously reported in another rural English speaking population [16]; but higher than the $2.4 \%$ overall rural estimate for the African region reported by the IDF in 2019 [1]. However, our observed prevalence is lower than the overall country prevalence of $5.8 \%$ reported by a recent systematic review [17] and values (7\% - 10.5\%) reported by other studies conducted in the French speaking regions of Cameroon [18] [19] [20]. This difference in prevalence may be attributed to differences in lifestyle between the English and French speaking contexts, or could be related to differences in the definition of diabetes as in the studies of Napoli et al., (2010) [18] and Lissock et al. (2011) [19] where a confirmation test for diabetes was not reported with possible misclassification of some diabetics. Our cut off screening age of $\geq 30$ years for participants in our study could also account for differences in prevalence from other studies which had a different or no cut off age.

Although diabetes prevalence in our population was relatively low, we observed a high number of persons with high risk of developing diabetes within 10 years (15.1\% of the population). If no interventions are initiated and implemented, we estimated that within 10 years, 65 new cases of type 2 diabetes will emerge in this study population, extending the overall prevalence from $3.8 \%$ to $10.7 \%$. The IDF (2019) [1] has also predicted that there will be a $47.5 \%$ surge in diabetes in the sub-Saharan African region by 2030.

A decade ago, it was argued that compared to urban, rural areas are less at risk of diabetes [21]; but recent data suggest otherwise. A recent systematic review did not find any difference in the prevalence of diabetes in urban and rural Cameroon [17]. In fact, some studies in Cameroon have found a higher prevalence of diabetes in rural compared to urban areas [19] [20]. Our current data corroborates these findings by demonstrating a very high proportion of individuals at high risk of type 2 diabetes in our rural population.

It is a possibility that some reports which have showed a lower diabetes prevalence in rural compared to urban areas were in part masked by the relative larger number of undiagnosed cases in rural areas. Indeed, we observed a very high proportion (67.6\%) of undiagnosed diabetes cases in our study population, mirroring the figure (68.8\%) we had previously reported in another rural population in Cameroon [16], but higher than the $60 \%$ reported by IDF for the African region [1]. As has been suggested by the IDF, this high rate of undiagnosed diabetes in our rural study population could be due to limited resources and non-prioritisation of screening. Indeed, our diabetes screening exercise leading to the current report was the first to have been conducted in the study population.

Apart from older age, we found no link between current diabetes in our study population and some typical diabetes risk factors (limited physical activity, 
overweight, obesity, family history of diabetes, and hypertension). On the other hand, all of these typical risk factors were statistically significantly associated with the risk of developing diabetes within 10 years. These results suggest that these typical risk factors of diabetes did not previously exist, but are now creeping into this rural population.

Our active population in this study was made up of CDC agricultural workers who perform manual labour on a daily basis compared to their semi-active counterparts who have adopted a relatively more sedentary lifestyle. This active population was, as expected, less likely to experience the risk factors of diabetes, and hence, less likely to be at risk of developing diabetes within 10 years. In the past both populations would have been very active with traditional lifestyles. As modernisation continues to creep into this rural population, there is bound to be changes in lifestyle even for this labour dependent active population. For example, if the CDC continues to introduce modern agriculture mechanisation techniques, these $\mathrm{CDC}$ workers will perform less manual labour and become less active and prone to developing diabetes in future. Of course, there are also many other factors that can precipitate the adoption of western life style increasing the diabetes risk of this population such as: access to the internet and social media, improvement of road infrastructure, allowing easy interaction between rural and urban areas and general increase in the standard of living of this rural population.

Given the eminent epidemiological transition for rural diabetes in Cameroon, the challenge is for the government to empower the healthcare system and foster collaboration with non-state actors to actively engage in preventive measures and management of those affected. Unfortunately, the national diabetes plan in Cameroon is only executed in urban areas with a regrettable lack of focus in rural areas. While the challenge of resources needed to provide healthcare in rural areas is appreciated, efforts have to be made to maximise existing resources and harness existing innovative approaches. For example, our successful award winning model [22] using student nurses and nurses to champion diabetes screening, sensitisation and care in rural areas, now being funded by WDF and Biaka University Institute of Buea in some rural communities in SW-Cameroon, could be adapted into the national diabetes plan along with other existing innovative approaches and rolled out.

\section{Conclusion}

We found a disturbing high proportion of persons with undiagnosed diabetes and at high risk of developing diabetes within 10 years in our rural study population, confirming the IDF recent observation that rural areas in sub-Saharan Africa are also at risk of a devastating diabetes crises in the nearest future. In addition to advocating for more allocation of funds, the national diabetes plan in Cameroon needs to make use of existing innovative approaches and expand the diabetes prevention and management services to reach the rural areas. 


\section{Acknowledgements}

We appreciate the technical and professional support offered by Health Research Foundation (HRF) Buea-Cameroon, the FAIMER Institute USA and the SW Regional Delegation for Public Health-Cameroon.

\section{Funding}

This project was co-funded by World Diabetes Foundation (WDF) and Biaka University Institute of Buea (BUIB) (Grant Number WDF16-1437).

\section{Contributions}

AZL, NMM and SEM conceptualized the study. All authors were involved in training of the nurses. SEM, OA, LDN, BPN, ADA, NBS, DE and ESN coordinated data collection and input. AZL and ADA analysed the data. All authors participated in writing the manuscript.

\section{Conflicts of Interest}

We declare no competing interests.

\section{References}

[1] IDF Diabetes Atlas. 9th Edition, 2019. https://www.diabetesatlas.org/upload/resources/2019/IDF_Atlas_9th_Edition_2019. pdf

[2] Mbanya, J.C., Kengne, A.P. and Assah, F. (2006) Diabetes Care in Africa. The Lancet, 368, 1628-1629. https://doi.org/10.1016/S0140-6736(06)69673-6

[3] Hossain, P., Kawar, B. and El Nahas, M. (2009) Obesity and Diabetes in the Developing World-A Growing Challenge.

[4] BeLue, R., Okoror, T.A., Iwelunmor, J., Taylor, K.D., Degboe, A.N., Agyemang, C., et al. (2009) An Overview of Cardiovascular Risk Factor Burden in Sub-Saharan African Countries: A Socio-Cultural Perspective. Global Health, 5, 10. https://doi.org/10.1186/1744-8603-5-10

[5] Hall, V., Thomsen, R.W., Henriksen, O. and Lohse, N. (2011) Diabetes in Sub Saharan Africa 1999-2011: Epidemiology and Public Health Implications. A Systematic Review. BMC Public Health, 11, 564. https://doi.org/10.1186/1471-2458-11-564

[6] Levitt, N.S. (2008) Diabetes in Africa: Epidemiology, Management and Healthcare Challenges. Heart, 94, 1376-1382. https://doi.org/10.1136/hrt.2008.147306

[7] Central Intelligence Agency (CIA) (2019) The World Factbook: Cameroon. https://www.cia.gov/library/publications/

[8] Pastakia, S.D., Pekny, C.R., Manyara, S.M. and Fischer, L. (2017) Diabetes in Sub-Saharan Africa: From Policy to Practice to Progress: Targeting the Existing Gaps for Future Care for Diabetes. Diabetes, Metabolic Syndrome and Obesity: Targets and Therapy, 10, 247. https://doi.org/10.2147/DMSO.S126314

[9] IndexMundi (2019) Cameroon Age Structure. https://www.indexmundi.com/cameroon/age_structure.html

[10] Maboh, M.N., Leke, A.Z. and Nyenti, P.B. (2019) Health Professions Education 
Programs Reorientation towards Social Accountability: The ENACIER Model. Social Innovation Journal, 55.

[11] Mavrogianni, C., Lambrinou, C.P., Androutsos, O., Lindström, J., Kivelä, J., Cardon, G., Huys, N., Tsochev, K., Iotova, V., Chakarova, N. and Rurik, I. (2019) Evaluation of the Finnish Diabetes Risk Score as a Screening Tool for Undiagnosed Type 2 Diabetes and Dysglycaemia among Early Middle-Aged Adults in a Large-Scale European Cohort. The Feel 4 Diabetes-Study. Diabetes Research and Clinical Practice, 150, 99-110. https://doi.org/10.1016/j.diabres.2019.02.017

[12] World Health Organization (2006) Definition and Diagnosis of Diabetes Mellitus and Intermediate Hyperglycaemia: Report of a WHO/IDF Consultation.

[13] Centre for Disease Control and Prevention (2017) Overweight and Obesity. https://www.cdc.gov/obesity/adult/defining.html

[14] World Health Organization (2011) Waist Circumference and Waist-Hip Ratio. Report of a WHO Expert Consultation, Geneva.

[15] Vandersmissen, G.J. and Godderis, L. (2015) Evaluation of the Finnish Diabetes Risk Score (FINDRISC) for Diabetes Screening in Occupational Health Care. International Journal of Occupational Medicine and Environmental Health, 28, 587-591. https://doi.org/10.13075/ijomeh.1896.00407

[16] Leke, Z.A., Cheryl, P. and Maboh, N. (2014) Breaking Barriers to Rural Diabetes Management in Rural Communities: Student Nurses Make a Difference Using Point-of-Care Testing. GSTF Journal of Nursing and Health Care, 1, 37-44. https://doi.org/10.5176/2345-718X_1.2.33

[17] Bigna, J.J., Nansseu, J.R., Katte, J.C. and Noubiap, J.J. (2018) Prevalence of Prediabetes and Diabetes Mellitus among Adults Residing in Cameroon: A Systematic Review and Meta-Analysis. Diabetes Research and Clinical Practice, 137, 109-118. https://doi.org/10.1016/j.diabres.2017.12.005

[18] Napoli, N., Mottini, G., Arigliani, M., Creta, A., Giua, R., Incammisa, A., Carotti, S., Sihom, F., Yimagou, I., Alombah, R. and Mbanya, J.C. (2010) Unexpectedly High Rates of Obesity and Dysglycemia among Villagers in Cameroon. Diabetes/Metabolism Research and Reviews, 26, 10-12. https://doi.org/10.1002/dmrr.1036

[19] Lissock, C.N.A.A., Sobngwi, E., Ngassam, E. and Ngoa, L.S.E. (2011) Rural and Urban Differences in Metabolic Profiles in a Cameroonian Population. Pan African Medical Journal, 10, 1. https://doi.org/10.4314/pamj.v10i0.72204

[20] Kaze, F.F., Meto, D.T., Halle, M.P., Ngogang, J. and Kengne, A.P. (2015) Prevalence and Determinants of Chronic Kidney Disease in Rural and Urban Cameroonians: A Cross-Sectional Study. BMC Nephrology, 16, 117.

https://doi.org/10.1186/s12882-015-0111-8

[21] Mbanya, J.C.N., Ngogang, J., Salah, J.N., Minkoulou, E. and Balkau, B. (1997) Prevalence of NIDDM and Impaired Glucose Tolerance in a Rural and an Urban Population in Cameroon. Diabetologia, 40, 824-829.

https://doi.org/10.1007/s001250050755

[22] Foundation for the Advancement of International Medical Education and Research (2015) Winners of the 2015 Projects That Work Competition.

https://www.faimer.org/news/tag/network-tufh/ 


\section{Appendix A}

\section{WDF16-1437/BUIB PROJECT \\ Form A \\ PRE-SCREENING FOR TYPE 2 DIABETES}

HEALTH AREA:

DATE:

Decision guide

\begin{tabular}{|c|c|}
\hline Age: & $<\mathbf{4 5}=0, \quad \mathbf{4 5 - 5 4}=2, \quad \mathbf{5 5 - 6 4}=3$ \\
\hline BMI: & $<25=0, \quad \mathbf{2 5 - 2 9 . 9}=1, \quad \geq \mathbf{3 0}=\mathbf{3}$ \\
\hline WHR: & $<$ M-0.90/F-0.80 = 0; M-0.90-0.99/F-0.80-0.85 = 3, \\
\hline BP: & Normal $=0, \quad$ abnormal $=2$ \\
\hline Family history of diabetes: & No $=0, \quad$ Yes (extended family) $=3$ \\
\hline Eligibility for screening: & $\leq \mathbf{5} / \mathbf{1 8}=$ not eligible $\quad>\mathbf{5} / \mathbf{1 8}=$ eligible \\
\hline
\end{tabular}

\begin{tabular}{|c|c|c|c|c|c|c|c|c|}
\hline PN & $\begin{array}{l}\text { Sex/ } \\
\text { Score }\end{array}$ & $\begin{array}{l}\text { Age/ } \\
\text { Score }\end{array}$ & BMI /Score & WHR/ Score & BP/Score & $\begin{array}{l}\text { Family history of } \\
\text { diabetes/score }\end{array}$ & $\begin{array}{l}\text { Total } \\
\text { Score/19 }\end{array}$ & $\begin{array}{l}\text { Eligible for } \\
\text { screening } \\
\text { (Yes/No) }\end{array}$ \\
\hline & & & & & & & & \\
\hline & & & & & & & & \\
\hline & & & & & & & & \\
\hline & & & & & & & & \\
\hline & & & & & & & & \\
\hline & & & & & & & & \\
\hline & & & & & & & & \\
\hline & & & & & & & & \\
\hline & & & & & & & & \\
\hline & & & & & & & & \\
\hline & & & & & & & & \\
\hline & & & & & & & & \\
\hline & & & & & & & & \\
\hline & & & & & & & & \\
\hline & & & & & & & & \\
\hline & & & & & & & & \\
\hline & & & & & & & & \\
\hline
\end{tabular}




\section{Appendix B}

\section{WDF16-1437/BUIB PROJECT \\ Form B \\ SCREENING FOR DIABETES}

HEALTH AREA:

DATE:

Decision guide

\begin{tabular}{|l|l|}
\hline FBG/RBS: & $<110 / 140 \mathrm{mg} / \mathrm{dl}=0, \quad 110-126 / 140-200 \mathrm{mg} / \mathrm{dl}=5, \quad>126 / 200 \mathrm{mg} / \mathrm{dl}=7$ \\
\hline Post Screening & $\bullet \quad$ Total score $<14=\mathrm{LR}$ \\
Decision: & $\bullet \quad$ Total score $\geq 14$, irrespective of FBS level $=$ HR, \\
& $\bullet \quad$ FBS $110-126 \mathrm{mg} / \mathrm{dl}$, irrespective of score $=$ HR \\
& $\bullet \quad$ FBS $>126 \mathrm{mg} / \mathrm{dl}$, irrespective of score $=$ PD $\left(2^{\mathrm{ND}}\right.$ FBS test required $)$ \\
\hline
\end{tabular}

\begin{tabular}{|c|c|c|c|c|c|c|}
\hline \multirow[t]{2}{*}{ PN } & \multirow{2}{*}{$\begin{array}{c}\text { Pre- } \\
\text { screening } \\
\text { Score }\end{array}$} & \multirow{2}{*}{$\begin{array}{c}\text { FBS/RBS } \\
\text { /Score }\end{array}$} & \multirow{2}{*}{$\begin{array}{c}\text { Total } \\
\text { Score } / 26\end{array}$} & \multicolumn{3}{|c|}{ Decision (Tick) } \\
\hline & & & & $\begin{array}{l}\text { Low } \\
\text { risk } \\
\text { (LR) }\end{array}$ & $\begin{array}{c}\text { High } \\
\text { risk } \\
\text { (HR) }\end{array}$ & $\begin{array}{l}\text { Potential diabetes case } \\
\text { (PD) } \\
\text { (Needs } 2^{\text {nd }} \text { testing) }\end{array}$ \\
\hline & & & & & & \\
\hline & & & & & & \\
\hline & & & & & & \\
\hline & & & & & & \\
\hline & & & & & & \\
\hline & & & & & & \\
\hline & & & & & & \\
\hline & & & & & & \\
\hline & & & & & & \\
\hline & & & & & & \\
\hline & & & & & & \\
\hline & & & & & & \\
\hline & & & & & & \\
\hline & & & & & & \\
\hline & & & & & & \\
\hline & & & & & & \\
\hline & & & & & & \\
\hline & & & & & & \\
\hline & & & & & & \\
\hline & & & & & & \\
\hline & & & & & & \\
\hline & & & & & & \\
\hline
\end{tabular}

Risk Scores Adapted from FINRISC Leke et al., 2018 